\title{
Biliary Pneumonia due to the Presence of a Bronchobiliary Fistula
}

\author{
Takeshi Matsumoto ${ }^{1,2}$, Kojiro Otsuka ${ }^{1}$, Satoshi Kaihara ${ }^{3}$ and Keisuke Tomii ${ }^{1}$
}

Key words: biliary pneumonia, bronchobiliary fistula, liver transplantation, transbronchial biopsy

(Intern Med 56: 1451-1452, 2017)

(DOI: 10.2169/internalmedicine.56.8066)

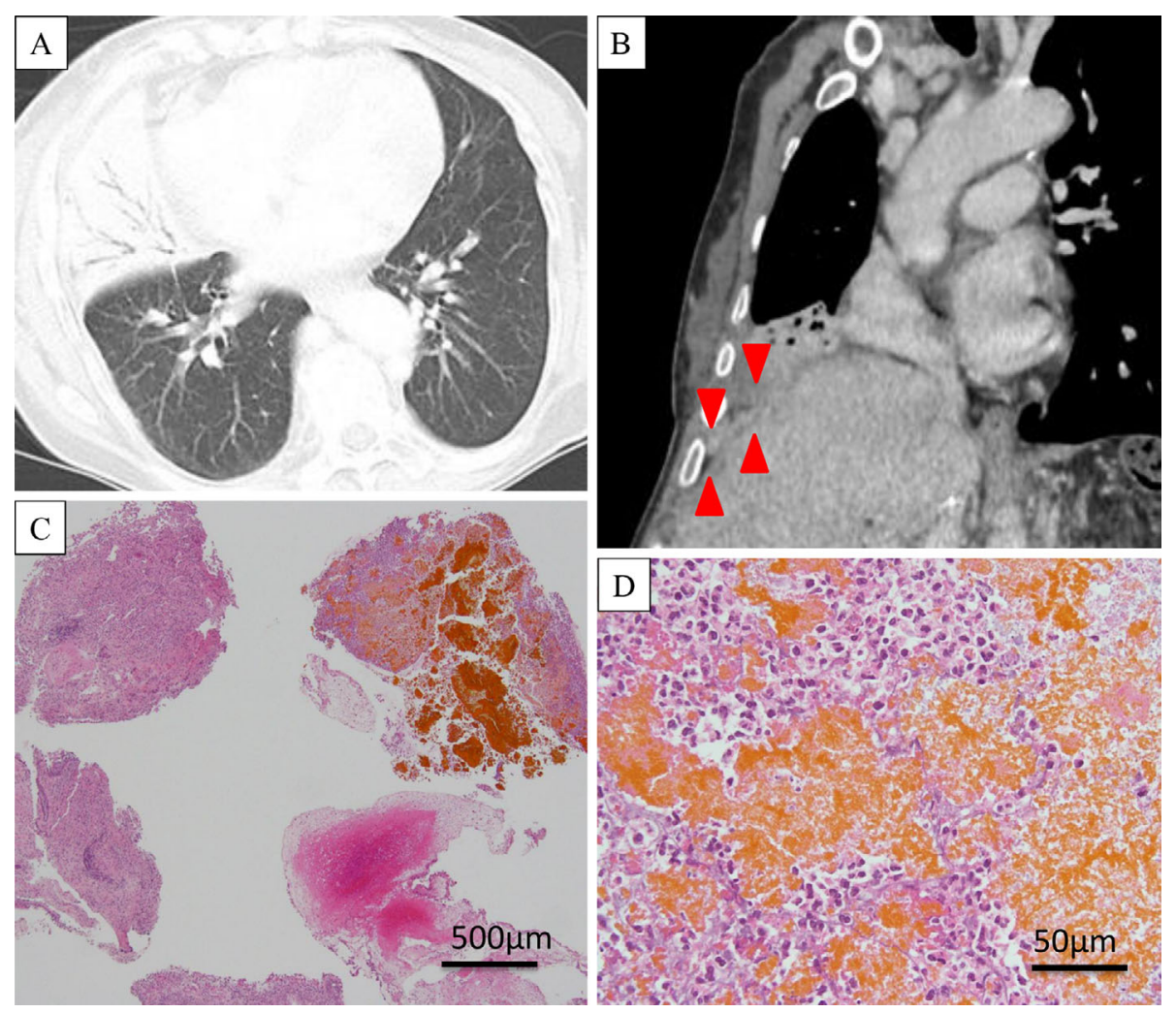

Picture.

A 56-year-old woman who underwent living liver transplantation for primary biliary cirrhosis seven years previously presented with symptoms of repetitive cholangitis. She had been suffering from a wet cough for the past three months and had also been treated for bacterial pneumonia, which tended to easily flare up. When referred to our hospital, computed tomography showed consolidation with an airbronchogram in the right lower lobe (Picture A). The presence of a fistula from the liver to the lung was suggested
(Picture B), but bile scintigraphy did not show any bronchial communication. Because bilious sputum was not apparently present, bronchoscopy was performed. The bronchoscopic lavage specimen was not bilious, but a transbronchial biopsy revealed bilious brown crystals surrounded by neutrophils (Picture C and D), leading to a diagnosis of biliary pneumonia due to bronchobiliary fistula. Bronchobiliary fistula is a rare disorder, and is clinically diagnosed based on the presence of bilious sputum (1). Although a bronchoscopic in-

${ }^{1}$ Department of Respiratory Medicine, Kobe City Medical Center General Hospital, Japan, ${ }^{2}$ Department of Respiratory Medicine, Graduate School of Medicine, Kyoto University, Japan and ${ }^{3}$ Department of Surgery, Kobe City Medical Center General Hospital, Japan Received for publication July 28, 2016; Accepted for publication September 20, 2016 Correspondence to Dr. Takeshi Matsumoto,fu_rinkazan0202@yahoo.co.jp 
spection rarely demonstrates the presence of such a fistula (2), a bronchoscopic biopsy of pneumonic lesions may be diagnostic even when the sputum findings are not bilious.

The authors state that they have no Conflict of Interest (COI).

\section{References}

1. Liao GQ, Wang H, Zhu GY, Zhu KB, Lv FX, Tai S. Management of acquired bronchobiliary fistula: A systematic literature review of 68 cases published in 30 years. World J Gastroenterol 17: 3842-3849, 2011.

2. Al-Mezem SS, Al-Jahdali HH. Chronic cough due to bronchobiliary fistula. Respiration 66: 473-476, 1999.

The Internal Medicine is an Open Access article distributed under the Creative Commons Attribution-NonCommercial-NoDerivatives 4.0 International License. To view the details of this license, please visit (https://creativecommons.org/licenses/ by-nc-nd/4.0/).

(C) 2017 The Japanese Society of Internal Medicine http://www.naika.or.jp/imonline/index.html 